STUDI

FRANCESI

\section{Studi Francesi}

Rivista quadrimestrale fondata da Franco Simone

186 (LXII | III) | 2018

Varia

\title{
MICHÈLE A. SCHAAL, Une troisième vague féministe et littéraire. Les femmes de lettres de la nouvelle génération
}

\section{Stefano Genetti}

\section{(2) OpenEdition}

\section{Journals}

\section{Edizione digitale}

URL: http://journals.openedition.org/studifrancesi/15879

DOI: 10.4000/studifrancesi. 15879

ISSN: 2427-5856

\section{Editore}

Rosenberg \& Sellier

\section{Edizione cartacea}

Data di pubblicazione: 1 décembre 2018

Paginazione: 534-535

ISSN: 0039-2944

\section{Notizia bibliografica digitale}

Stefano Genetti, «MICHĖLE A. SCHAAL, Une troisième vague féministe et littéraire. Les femmes de lettres de la nouvelle génération», Studi Francesi [Online], 186 (LXII | III) | 2018, online dal 01 janvier 2019, consultato il 06 janvier 2021. URL: http://journals.openedition.org/studifrancesi/15879 ; DOI: https://doi.org/ 10.4000/studifrancesi. 15879

Questo documento è stato generato automaticamente il 6 janvier 2021.

\section{(c) (i) (9)}

Studi Francesi è distribuita con Licenza Creative Commons Attribuzione - Non commerciale - Non opere derivate 4.0 Internazionale. 


\title{
MICHÈLE A. SCHAAL, Une troisième vague féministe et littéraire. Les femmes de lettres de la nouvelle génération
}

\author{
Stefano Genetti
}

\section{NOTIZIA}

MICHÈLE A. SCHAAL, Une troisième vague féministe et littéraire. Les femmes de lettres de la nouvelle génération, Leiden-Boston, Brill-Rodopi, 2017, «Faux titre» 415, 343 pp.

1 Preferendo, nel titolo, la canonica dicitura femme de lettres ai termini écrivaine o auteure, pure utilizzati nel testo, M.A. Schaal fornisce, nei quattro capitoli che compongono questo volume, un'articolata analisi di altrettanti romanzi ritenuti emblematici delle istanze che, tra rotture e continuità, contraddistinguono il rinnovarsi e diversificarsi dell'attivismo e del pensiero femministi nella seconda metà degli anni Novanta. Oggetto di indagine sono: Truismes (1996) di Marie Darrieussecq, dove l'anonima narratrice contesta i pregiudizi sessisti eteronormativi derivanti da una visione univoca e immobilista del femminile, valorizzando invece l'adattamento a contesti diversi e la conciliazione dei contrari; Les jolies choses (1998) di Virginie Despentes, letto come un Bildungsroman dove l'identità si costruisce al confluire di virilità e femminilità e dove le gemelle antagoniste Claudine e Pauline sono allo stesso tempo vittime e complici del sistema patriarcale incarnato dai personaggi maschili; Viande (1999), nel quale Claire Legendre mette a tema la violenza di genere recuperando le convenzioni letterarie del conte erotico e trasformando le due protagoniste ridotte a oggetti sessuali in novelle Justine e Juliette; infine, Garçon manqué (2000) di Nina Bouraoui, dove la narratrice, nata dal matrimonio tra una francese e un algerino, cresciuta ad Algeri e trapiantata a Rennes, rivendica un'identità indecidibile, le cui oscillazioni investono tanto il discorso sulle origini, i conflitti etnici e lo sradicamento quanto l'orientamento sessuale. 
2 Scritture di donne significa scritture femministe? Se lo chiede, nell'«Avant-propos» (pp. IX-XII), Gill RYE, che parla di femminismo implicito in merito a scrittrici che prendono posizioni diverse in materia, sfumate nel caso di Darieussecq e Bouraoui: più radicali nel caso di Despentes e Lengedre. G. Rye sottolinea inoltre come un merito di questo libro sia proprio di non esagerare la portata politica di romanzi che tuttavia rispecchiano «[u]n contexte économique et sociopolitique paradoxal qui engendre la persistance de discriminations et de l'altérisation genrée, la multiplicité et les contradictions des perspectives ou des personnalités, l'intersectionnalité des différences, les questions sexuelles ou identitaires, l'hybridité ou le genre comme performance: autant d'aspects de cette troisième vague féministe» (p. 44). Di questa terza ondata - come è noto, la prima, a dominante riformista ed egalitaria, corrisponde grossomodo alla Terza Repubblica, mentre la seconda, incentrata sulle specificità femminili, agli anni Sessanta-Ottanta-l'A. traccia la cartografia nella corposa e documentata «Introduction» intitolata «Nouvelles écrivaines, nouvelles féministes: mêmes combats (?)»(pp.1-47). Lo fa in un'ottica attenta non solo alle questioni dibattute-procreazione assistita, omoparentalità, pornografia, prostituzione - ma anche all'interazione tra forme di militanza, elaborazioni teoriche e pratiche letterarie, rinunciando a ricondurre questa mappatura a una coerenza non solo chimerica ma anche sconfessata, e aggiornandola, in relazione a voci emergenti quali Wendy Delorme, Faïza Guène e Lola Lafon, agli sviluppi più recenti, caratterizzati da un'accresciuta sensibilità per le minoranze - basti pensare alle polemiche sul port $d u$ voile o sul mariage pour tous - e dall'incidenza delle modalità di reinvenzione di sé e di socializzazione, ma anche di esclusione e violenza, che le nuove tecnologie e le realtà virtuali possono comportare («Vers une quatrième vague féministe?», pp. 283-293).

3 Se echi del costruttivismo di S. de Beauvoir, del femminismo materialista (M. Wittig), psicanalitico (L. Irigaray) e differenzialista (H. Cixous) risuonano qui e là nel corpus preso in esame, gettando un fragile ponte verso il passato, a essere complessivamente rifiutati sono un certo femminismo storico in quanto espressione elitaria dell'universalismo alla francese e, più in generale, ogni abusiva generalizzazione sulla condizione e sulla creatività femminili. Per influsso degli studi di genere, culturali e postcoloniali anglo-americani, dei quali l'A. evidenzia la tardiva istituzionalizzazione universitaria in Francia all'inizio del nuovo millennio, è una concezione plurale e ibrida, nomadica e performativa dell'identità sessuale e di genere che i testi studiati restituiscono, traducendola in voci narranti equivoche e focalizzazioni multiple. Da un lato, l'intersezionalità induce a ripensare l'identità di genere in connessione con un complesso di fattori psico-fisici e socio-culturali spesso contraddittori; dall'altro, persistono l'inestricabilità di personale e politico di cui queste scritture dell'io testimoniano e le forme di consapevolezza e di resistenza che mirano a stimolare. Se, sul piano tematico, nelle opere delle autrici studiate così come in C. Angot, C. Cusset o C. Millet, i limiti della rappresentazione del corpo e della sessualità si estendono alle mestruazioni e all'aborto, alla masturbazione, allo stupro e all'incesto, ai disturbi alimentari e all'automutilazione, le tensioni che attraversano il quadro dinamico delineato da M.A. Schaal si riflettono nella scivolosa visibilità editoriale acquisita da queste scrittrici - spesso etichettate in base al loro sesso o genere, come denuncia Virginie Despentes nel suo manifesto King Kong théorie (p.40) - e nella controversa ricezione, anche in ambito femminista, dei loro romanzi, ora celebrati perché trasgressivi, liberatori, ora tacciati di riprodurre un immaginario fallocentrico e degradante. 